\title{
Predictors of tobacco use initiation in adolescents: a two-year prospective study and theoretical discussion
}

Dennis R Wahlgren, Melbourne F Hovell, Donald J Slymen, Terry L Conway, C Richard Hofstetter, Jennifer A Jones

\begin{abstract}
Objective-To test whether baseline data from a randomised clinical trial are predictive of initiation of tobacco use over a two-year follow-up interval, and to discuss results in the context of a theoretical model.

Design-Secondary, non-experimental analyses of data collected from a prospective cluster-randomised clinical trial comparing an intervention with a control condition for reduction of tobacco incidence rates. Orthodontic offices in southern California were recruited and randomised to an experimental or control group. Patient participants were sampled within each office, and completed a short survey, repeated two years later.
\end{abstract}

Subjects-13 923 patients, 11-18 years of age, randomly sampled from each office.

Main outcome measures-The ability of baseline data to predict initiation of tobacco use over the two-year follow-up interval was tested through a series of logistic regression models. Significant predictors and their interactions were identified in fixed-effects models, and verified in a mixed-effects logistic regression model to account for cluster randomisation.

Results-Clinician advice against tobacco use was associated with a lower rate of tobacco use initiation among young people whose peer group considered smoking socially desirable. Rates of initiation increased with age, but this association differed by gender and by whether the adolescent had been offered tobacco within 30 days prior to the baseline assessment. People from minority groups were less likely to initiate tobacco use than whites, and young people engaging in other risk practices were more likely to initiate tobacco use.

Conclusions-Findings support predictions based on learning theory that social processes are critical in the development of health-risk behaviours. Future preventive efforts should target changing the density with which young people encounter pro- and anti-tobacco prompts and consequences in the community.

(Tobacco Control 1997;6:95-103)

Keywords: tobacco initiation; adolescents; prospective predictors

\section{Introduction}

More than 400000 deaths per year in the $\vec{\omega}$ United States are directly attributed to tobacco use. ${ }^{1}$ Despite declines in tobacco use in adults use among adolescents may be increasing. ${ }^{2} 0$ Tobacco use is initiated predominantly duringo childhood and adolescence: nearly $90 \%$ of per- sons who have ever smoked a cigarettec reported that they tried their first cigarette by the age of $18 .{ }^{3}$ Many of these young people will ${ }^{\mathbb{D}}$ smoke an average of 16 years before quitting. 8 Understanding the factors that lead a child or adolescent to begin using tobacco is critical too the development of effective interventions to prevent tobacco use.

A substantial body of research has examined $\stackrel{\nu}{\circ}$ factors associated with the onset of tobacco $\stackrel{\Omega}{\rightarrow}$ use. Much of this literature suggests that start-윽 ing to use tobacco is a socially learned $\frac{J}{\sigma}$ behaviour influenced by individual differences, family and peer influences in the social environment, as well as environmental and cul-음 tural influences.

Recent studies have identified a need for prospective research, and research which is driven by theoretical predictions rather than data explorations. ${ }^{56}$ Most of the previous studies into tobacco use determinants have been. cross-sectional, which has been useful for sug-o gesting potentially important factors related to the initiation of tobacco use. However, $\stackrel{5}{\circ}$ prospective longitudinal research is particu $\frac{7}{0}$ larly important for better understanding causal factors instrumental in the initiation of tobaccoo use.

Substantially fewer longitudinal studies of tobacco use initiation have been conducted.0 Several notable exceptions have been reviewedo by Conrad and colleagues. ${ }^{5}$ This review found $\overparen{\Phi}$ strong support for several categories of predic-? tors of smoking onset including socioeconomic $\frac{T}{0}$ status and social learning variables. The review $\frac{\overrightarrow{0}}{\mathbb{D}}$ also cited support for social bonding variables, $\frac{?}{\mathbb{Q}}$ self-efficacy regarding refusal skills, intentions, $\stackrel{\varrho}{\square}$ attitudes, knowledge, and indicators of self-esteem. ${ }^{5}$ Other studies have examined dis-응 positional attributes, such as rebelliousness, rejection of adult authority, personalo dissatisfaction, and need for peer approval as determinants of smoking initiation. ${ }^{7}$ Although these constructs have consistently predicted onset of tobacco use in young people overall, there are inconsistencies across various subgroups suggesting that the predictors may 
Table 1 Correlates of current tobacco use examined for predictive utility *

Demographic

Age (age at baseline, calculated from birth date obtained from patient chart)

Gender (determined from patient chart before baseline interview)

Parent education ("Have either of your parents or has anyone you live with graduated from college?")

Ethnicity ("Would you describe yourself as white, black, Hispanic, Asian, or other?"-four dummy variables, reference = white)

Experimental manipulation

Experimental group (intervention vs control)

Correlates of current tobacco use

Seat belt use ("Do you usually wear a seat belt when you ride in cars?")

Weight ("Do you think you weigh too much? Too little?"- coded into one dichotomous variable: content/underweight, overweight)

Floss teeth ("Do you usually floss your teeth at least once a day?")

Brush teeth ("Do you usually brush your teeth at least twice a day?")

Sleep ("Do you usually get eight or more hours of sleep each night?")

Alcohol use ("Have you ever had any beer, wine, or other alcoholic beverage?")

Live with tobacco user ("Does anyone you live with smoke cigarettes, pipes, cigars, or use smokeless tobacco?")

Offered past month ("In the past 30 days have you been offered a cigarette, pipe, cigar or any form of smokeless tobacco?")

Friends think "cool" ("Do most of your friends think people who smoke look 'cool' and 'more grown-up'?")

Friends make fun ("Do most of your friends make fun of people who smoke or use smokeless tobacco?")

Friends avoid ("Do most of your friends avoid people who smoke or use smokeless tobacco?")

$\star$ Coding of items is displayed in tables 2 and 3 .

perform differentially at different ages and across gender and race/ethnic subgroups.

Many conceptual and practical problems exist with the use of such cognitive and dispositional predictors, however. These constructs are reified entities based on verbal reports, and cannot be directly manipulated. Whether one tends to ignore or violate rules, laws, or adult direction, how one feels about oneself, and the degree to which an individual finds peer approval rewarding are the products of individuals' histories in their social environments. At best, these measures may serve only to focus preventive measures in a more tailored fashion according to individual differences. Learning theory provides an empirically established foundation for health behaviour research which does not rely on postulation of such mediating variables. ${ }^{8} 9$ Learning theory directs research into the effects of one's history in a rich and complex social environment which shapes not only observable behaviours, such as smoking or refusing peer pressure, but also verbal behaviour, such as reports of tendencies to act in certain ways-for example, anti-smoking attitudes-or reports of one's confidence in engaging in a behaviour (self-efficacy).

Analyses presented in this report extend our previous work which identified cross-sectional correlates of current tobacco use in an ethnically diverse sample of southern California adolescents undergoing orthodontia. ${ }^{10}$ This paper examines the prospective usefulness of selected demographic, social, and risk-taking variables as learning theory-based predictors of tobacco use initiation over a two-year period among adolescents who had never previously used tobacco.

\section{Methods}

Data for these analyses were collected as part of "Smiles Plus," a randomised clinical trial which tested a clinician-delivered intervention to reduce rates of smoking initiation in adolescents. ${ }^{11}$ Orthodontic offices were randomly assigned to experimental and control groups, and experimental offices received tobacco use prevention training and antitobacco materials, and were reimbursed for writing anti-tobacco "prescriptions" for their adolescent patients.

\section{SUBJECTS}

Random samples (58\%) of 11-18-year-old orthodontic patients were selected from 154 offices of orthodontists who agreed to participate in the study. Fifty-eight per cent of each office's patients were sampled, as this represented the average number of age-eligible patients per office necessary to achieve statistical power for analysis of the larger trial outcome. At baseline, 16915 patients took part in a five-minute survey using a telephone interview, or by mailed questionnaire for those who could not be reached by telephone, following solicitation of informed consent from parents. Interviews were completed for over $94 \%$ of participants contacted. A second wave of telephone interviews/mailed questionnaires was completed two years after the initial wave. Vigorous tracking procedures ${ }^{12}$ resulted in follow-up interviews conducted for $92.5 \%$ of the initial cohort.

Mean age of participants at baseline was 14.4 years (SD 1.79) and $54.3 \%$ were female. Most participants were white $(72.9 \%)$, while 12.5\% were Latino, 9.0\% Asian, $2.7 \%$ black, and $2.6 \%$ other. About $0.3 \%$ of participants refused to identify their ethnicity.

\section{MEASURES}

Subjects were asked 24 questions covering demographics, health attitudes and behaviours, social support for tobacco use, and intentions to use tobacco. The subset of items included in the present analyses are shown in table 1. Predictors were selected for analysis based on theoretical predictions from learning theory, ${ }^{89}$ or from previous empirical findings. ${ }^{13}$ To ease interpretation, all dichotomous predictors (except the ethnicity dummy variables) were coded such that zero represented lower theoretical risk, and one represented higher risk. Therefore, odds ratios predicting initiation of smoking were predicted to be greater than 1.0.

Test-retest reliability was greater than $95 \%$ for all items. ${ }^{10}$ Limited construct validity of the central tobacco-use question, "Have you ever 
smoked a cigarette, pipe, cigar, or used any form of smokeless tobacco?" was assessed from baseline data using Kendall's $\sigma-b$ statistic. Based on theoretical foundations and findings from previous research, four measures were hypothesised to be positively associated with tobacco use: age $(\sigma-b=0.28)$, alcohol use ever $(\sigma-b=0.41)$, living with a tobacco user $(\sigma-b=$ 0.12 ), and accepting a friend's offer of tobacco $(\sigma-b=0.40)$. Two measures were hypothesised to be negatively associated with tobacco use: having friends who make fun of tobacco users $(\sigma-b=-0.08)$, and having friends who avoid tobacco users $(\sigma-b=-0.37)$. All associations were in the expected directions and most were modest or large coefficients, thus supporting the validity of the tobacco use item.

ANALYSES

Subjects who asserted that they had not "ever smoked a cigarette, pipe, cigar, or used any form of smokeless tobacco" at baseline were classified as non-users at baseline and constitute the cohort used in these analyses. About 18\% (2992) of the baseline cohort of 16915 participants were excluded from analyses due to any tobacco use before the baseline assessment (resulting baseline $\mathrm{n}=13$ 923). Subjects were classified as tobacco initiators or non-initiators according to their responses to the same question repeated during the follow-up interview two years later.

Cross-sectional multivariate analyses of the baseline data resulted in the identification of several correlates of 30-day tobacco use. ${ }^{10}$ The variables associated with concurrent tobacco use formed the basis for the present analyses of predictors of incidence, and are shown in table 1. Because the analysis plan was to include all items in simultaneous logistic multiple regressions, multicolinearity was first examined through a principle components factor analysis (PCA) across the set of predictors, and through examination of their bivariate correlation matrix.

Using multiple logistic regression, tobacco initiation was regressed on baseline predictor variables. An affirmative response to this question reflected the incidence of tobacco use at any time during the two-year period from baseline to follow up. Predictors that reached statistical significance at the $\mathrm{P}<0.05$ level were retained for further analysis. Demographic and structural variables-for example, experimental group-were included in all models regardless of significance level for the purpose of statistical control.

To examine potential differential effects of age, gender, ethnicity, and experimental group, interaction terms were computed for these factors by the remainder of the predictors. A series of multiple logistic regression analyses was used to examine the predictive utility of the interaction terms. The first analysis regressed the "ever used tobacco" outcome on the main effect variables and the set of age-bymain-effect interaction terms. The second analysis substituted gender-by-main-effect interaction terms for the age-by-main-effect interaction terms. Analyses were repeated using sets of group and ethnicity interaction terms. All ethnicity-by-main-effect interaction terms were included-for example, black-by웅 seatbelt use, hispanic-by-seatbelt use-in the latter analysis.

We adopted two criteria for retention ob interaction terms. Interaction terms that (a) attained statistical significance at $P<0.01$, op (b) were nearly significant and theoreticall meaningful, were retained for further analysis음 The exception to these criteria was for ethnic $\frac{\bar{c}}{5}$ ity interaction terms. Because ethnicity wa® represented as a set of four dummy variableson the significance criterion for retention of the ethnicity interactions was set at a quarter of the above level ( $\mathrm{P}<0.0025)$, and at least two eth $\vec{\omega}$ nicities had to interact with a predictor variable for the set of ethnicity-by-predictor interactions terms to be retained.

With these exceptions it was expected that even very small relationships would be statisti옥 cally significant, due to the large sample size? Given the exploratory nature of the present study, however, this liberal approach was deemed appropriate to prevent overlooking small but potentially important relationships, that is, to avoid type II error.

Because the unit of randomisation in the study was the orthodontic office rather than the level of the individual patient, within-officen clustering effects not accounted for in the口 model may artificially reduce the standard errors of the coefficients and yield smaller $\frac{0}{3}$ more significant probability values. In accordance with the exploratory nature of the analyses, and to facilitate the fitting of severa screening models, the initial regressiono analyses were conducted without taking this๊

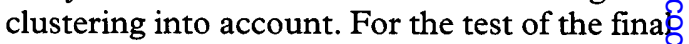
model, however, a logistic mixed-effects multi옥 ple regression was conducted, entering the sig흘 nificant main effects from the first analysis, the interaction terms that were retained from the subsequent analyses, and a random-effects term to account for clustering within orthodontic office. ${ }^{14}$

Analyses were conducted using SPSS $/ \mathrm{PC}+{ }^{1}$ ? and EGRET ${ }^{14}$ statistical software.

\section{Results}

Inspection of the bivariate correlations, PCA results, and standard errors for the regression coefficients of the predictors suggested limited to no multicolinearity. Therefore, all independ옫 ent variables were retained for logisties regression analyses.

Regression analyses were conducted on sample sizes ranging from 10645 to $10695 \mathbb{8}$ This decrease from the baseline cohort of 16915 participants represents an approxi $\frac{0}{\sigma}$ mately $7.5 \%$ decrease due to patients lost to follow up, $18 \%$ due to ineligibility (tobacco use before the baseline), and about $11.5 \%$ due tos. missing data on one or more variables (eithef baseline predictor or follow-up outcome).

Answers to the question at follow up: "Have you ever smoked a cigarette, pipe, cigar, or used any form of smokeless tobacco?" were regressed on all baseline predictors simultaneously (table 2). Two health practices (Brush 
Table 2 Fixed effects logistic regression of smoking incidence on main effects

\begin{tabular}{|c|c|c|c|c|c|c|}
\hline \multirow[b]{2}{*}{ Variable } & \multicolumn{2}{|c|}{ Data code } & \multicolumn{2}{|c|}{ At risk $(\%)^{\star}$} & \multirow[b]{2}{*}{ Odds ratio } & \multirow[b]{2}{*}{$P$} \\
\hline & 0 & 1 & Non-initiators & Initiators & & \\
\hline Parent education & Yes & No & 26 & 28 & 1.015 & 0.772 \\
\hline Age & NA & NA & $14.0 \dagger$ & $14.5 \dagger$ & 1.051 & $<0.001$ \\
\hline Gender & F & $M$ & 44 & 48 & 1.103 & 0.043 \\
\hline Group & Intervention & Control & 51 & 53 & 1.089 & 0.066 \\
\hline Black & White & Black & 3 & 2 & 0.575 & $<0.001$ \\
\hline Hispanic & White & Hispanic & 11 & 14 & 1.036 & 0.625 \\
\hline Asian & White & Asian & 11 & 7 & 0.672 & $<0.001$ \\
\hline Other ethnicity & White & Other & 2 & 3 & 1.002 & 0.990 \\
\hline Seat belt & Yes & No & 4 & 7 & 1.342 & 0.003 \\
\hline Weight & $\mathrm{U} / \mathrm{C}$ & Over & 20 & 25 & 1.205 & $<0.001$ \\
\hline Floss & Yes & No & 62 & 69 & 1.156 & 0.003 \\
\hline Brush & Yes & No & 8 & 9 & 1.106 & 0.243 \\
\hline Sleep & Yes & No & 16 & 22 & 1.084 & 0.182 \\
\hline Alcohol & No & Yes & 33 & 61 & 2.647 & $<0.001$ \\
\hline Live with tobacco user & No & Yes & 25 & 32 & 1.258 & $<0.001$ \\
\hline Offered tobacco past month & No & Yes & 4 & 14 & 2.310 & $<0.001$ \\
\hline Friends think "cool" & No & Yes & 5 & 8 & 1.264 & 0.013 \\
\hline Friends make fun & Yes & No & 59 & 57 & 0.820 & $<0.001$ \\
\hline Friends avoid tobacco & Yes & No & 20 & 33 & 1.492 & $<0.001$ \\
\hline
\end{tabular}

* Percentage at risk (coded " 1 ") among those who did not initiate tobacco use and those who did initiate use.

$\dagger$ Mean age in each group displayed.

$\mathrm{NA}=$ not applicable; $\mathrm{U} / \mathrm{C}=$ underweight or content with weight.

teeth, and Sleep 8 hours) did not attain statistical significance $(\mathbf{P}>0.05)$ and were excluded from subsequent analyses.

Interaction terms were computed for age, gender, race, and experimental group by the remainder of the predictors, and the predictive utility of these interaction terms was examined using a series of multiple logistic regressions. The first such analysis regressed the "ever used tobacco" outcome on the main effect variables plus the set of age-by-main-effect interaction terms. The only age-by-main-effect interaction term to reach the $P<0.01$ significance level was age-by-gender (odds ratio $(\mathrm{OR})=1.087$ ). Because age-by-offered-last-month was nearly significant by this criterion, $(\mathrm{OR}=0.882, \mathrm{P}=$ 0.012 ), and was considered theoretically meaningful, this interaction was retained. No age-by-ethnicity interactions met the retention criteria.

The second analysis was identical, with the substitution of the set of gender-by-main-effect interaction terms for the age-by-main-effect interaction terms. This analysis produced only one significant interaction, age-by-gender, as above, with a similar OR (1.097). The regression which included the set of group-bymain-effect interaction terms produced no significant interaction terms, but resulted in one marginal variable (group-by-friends-think"cool", $\mathrm{OR}=1.616, \mathrm{P}=0.012$ ) which was deemed theoretically meaningful, and retained for further examination. The regression which included the four sets of ethnicity-by-maineffect interaction terms revealed only one significant interaction term by the $\mathrm{P}<0.0025$ criterion (age-by-Hispanic, $O R=0.869$ ). This term was not retained for further analyses because it was not corroborated by statistical significance of other age-by-ethnic-group interactions.

The meaningfulness of the three retained interactions (age-by-gender, age-by-offeredlast-month, and group-by-friends-think"cool") was scrutinised by visual examination of the bivariate plots (figures 1-3). Figure 1 shows that rates of initiation are similar for boys and girls until age 14, after which boys are increasingly more likely to begin smoking. Figure 2 shows that rates of initiation increase much faster for 11-13 year olds who have been offered tobacco compared with those who have not been offered tobacco. Finally, figure 3 shows that young people who reported having friends who think smoking looks "cool" were less likely to initiate tobacco use if they were in an office assigned to the counselling prevention programme than were those in an office assigned to the control condition. These interactions were retained for further analyses.

To examine the final model, a logistic mixed-effects multiple regression was conducted using the EGRET routine. ${ }^{14}$ Tobacco-use status at follow up was regressed on the set of main effects derived from the first analysis, the interaction terms retained from the previous set of analyses, and a random-effects term to account for clustering within orthodontic office. Results are presented in table 3. Results are not presented for the random-effects term because clustering is considered a "nuisance" parameter and not of interest. This final model was tested for 10692 subjects for whom all data were present.

The three interaction terms, age-by-gender, age-by-offered-last-month, and group-byfriends-think-“cool", were significantly predictive of tobacco use initiation. The main effects

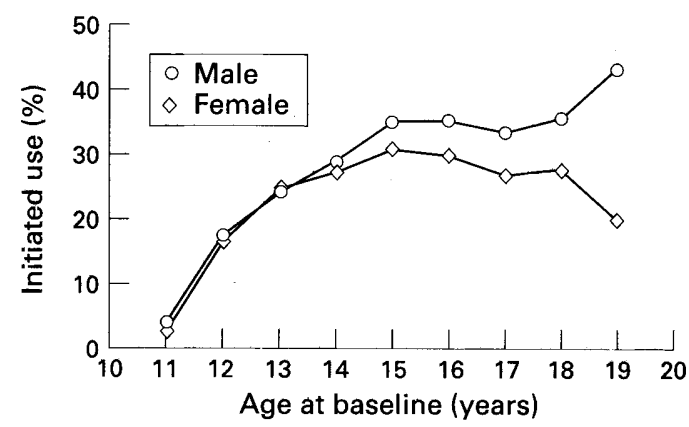

Figure 1 Proportion of each baseline age category who initiated tobacco use during the follow-up interval, stratified by gender. 


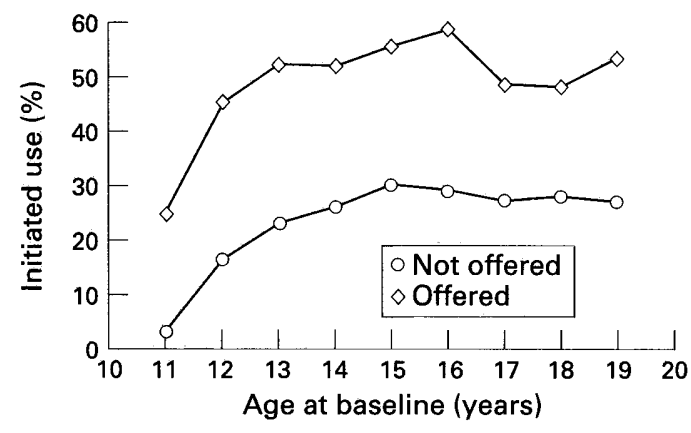

Figure 2 Proportion of each baseline age category who initiated tobacco use during the follow-up interval, stratified by whether the participant had been offered tobacco within 30 days prior to the baseline interview.

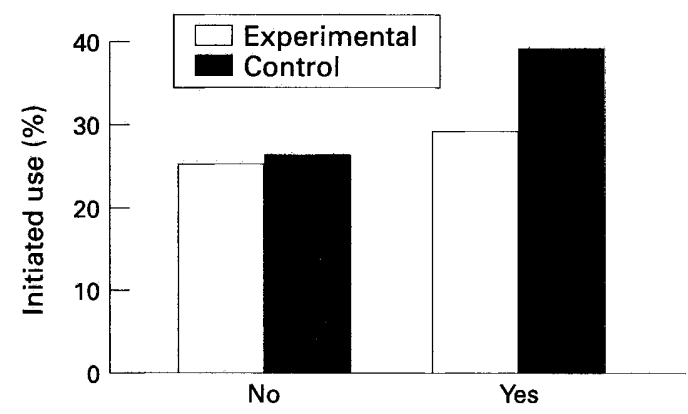

Friends think smoking is "cool"

Figure 3 Proportion of participants who initiated tobacco use during the follow-up interval, stratified by experimental group and whether they had friends who think smoking is "cool" at baseline.

which comprise these interactions are not interpretable as main effects and are therefore shown in parentheses in table 3. Black and Asian ethnicity were both predictive of lower initiation rates compared with whites. Engagement in other health-risk behaviours, such as alcohol consumption, or lack of participation in health-protective behaviours-for example, seat belt use, teeth flossing-were predictive of greater tobacco use initiation rates. Considering oneself overweight, living with a tobacco user, and lacking friends that avoid tobacco users also predicted initiation. Having friends who make fun of tobacco users was also predictive of initiation, but opposite to the predicted direction.

\section{Discussion}

Because interactions supersede their constituent main effects, we begin with consideration of the significant interactions in the final model. With increasing age comes increased opportunities for initiation of tobacco use. However, these data suggest the effect is moderated by both gender and whether the adolescent has been presented with an explicit opportunity to try tobacco. Age was taken from the baseline interview, and tobacco use initiation could have occurred at any point during the two-year follow-up interval. As apparent from figure 1 , rates of initiation of tobacco use are similar for boys and girls until age 14, after which young men begin smoking at a greater rate. The social ecology changes near the age of 14 , particularly because most young people are changing from junior high or middle school level (ages 11-14 years) to sen- ior high school level (ages 15-18). The pressures to conform in ways that appear more mature may be greater for young men, but the exact mechanisms behind this age/gender interaction are unclear. The age effect also was moderated by presentation of opportunity Figure 2 shows that tobacco use initiation rates. increased dramatically for 11-13 year olds whọ had been offered tobacco within 30 days priog to baseline, and stabilised at roughly $50 \%$ 올 whereas rates increased at a slower rate fof those not offered tobacco, stabilising at aboup $30 \%$ at age 15 .

The experimental intervention to reduce initiation rates appears to have been moderated by the presence of peers who consider smokinge socially desirable. (Note that the group main effect is to be ignored in the presence of this significant interaction in the model.) As showin in figure 3, among adolescents who lacked friends who think it is "cool" to smoke, tobacco use initiation rates were similar for the experimental and control groups. However, amon£ those who reported having friends who $\mathrm{d}$ consider smoking "cool", more participants began using tobacco, with about $10 \%$ more in the control group than in the experimental group. This suggests that exposure to the experimental intervention-that is, exposure to repeated prompts by one's orthodontist t@ never begin using tobacco-may havळิ conferred some protection against the peer pressure implied by having friends who think is is "cool" to smoke. The effect of such repeated exposure to personal anti-tobacco promptin may inoculate otherwise vulnerable adoles $=$ cents against the effects of peer prompts tके experiment with tobacco use. The counselling employed in our study did not explicitlp address peer pressure and the notion tha? tobacco use is "cool" or socially desirable. If this observed interaction is real, the addition of this to the counselling should provide for $\mathbb{P}$ more potent and tailored interventions Further, explicit skills training to resist this sor of peer pressure would likely prove more effeco tive yet. Because of the non-experimentas nature of this finding, the validity of this intero action effect requires experimental verification

Of the significant main effects that were not part of significant interactions, all but one were in the predicted direction. Blacks and Asiansi were almost half as likely to begin smoking as whites. The literature is inconsistent witle respect to racial/ethnic differences in tobacce initiation. ${ }^{3}$ The differences across studies, however, may be due to differences in outcomf measures (such as susceptibility $v$ actuad initiation), different predictors included irâp multivariate models, or regional/geographical differences. ${ }^{3}$ Maddahian, Newcomb, and Bentler, ${ }^{16}$ however, found that ethnie differences in initiation rates among Californiaf youth were diminished when ease of cigarette acquisition from friends was taken into account. This latter variable was not assessed in our study and may account for the differences seen by ethnicity.

Considering oneself overweight conferred greater risk of starting tobacco use, as did 
Table 3 Mixed effects logistic regression of smoking incidence on main effects * and interactions

\begin{tabular}{|c|c|c|c|c|c|}
\hline \multirow[b]{2}{*}{ Variable } & \multicolumn{2}{|c|}{ Data code } & \multirow[b]{2}{*}{$O R$} & \multirow[b]{2}{*}{$95 \% C I$} & \multirow[b]{2}{*}{$P$} \\
\hline & 0 & 1 & & & \\
\hline Parent education & Yes & No & 1.017 & 0.916 to 1.128 & 0.755 \\
\hline (Age) & NA & NA & 1.086 & 0.953 to 1.237 & 0.215 \\
\hline (Gender) & $\mathrm{F}$ & $\mathrm{M}$ & 0.294 & 0.137 to 0.632 & 0.002 \\
\hline (Group) & Control & Intervention & 0.662 & 0.441 to 0.993 & 0.046 \\
\hline Black & White & Black & 0.568 & 0.420 to 0.769 & $<0.001$ \\
\hline Hispanic & White & Hispanic & 1.054 & 0.911 to 1.220 & 0.481 \\
\hline Asian & White & Asian & 0.682 & 0.571 to 0.814 & $<0.001$ \\
\hline Other ethnicity & White & Other & 1.009 & 0.753 to 1.352 & 0.954 \\
\hline Seat belt & Yes & No & 1.369 & 1.128 to 1.661 & 0.001 \\
\hline Weight & $\mathrm{U} / \mathrm{C}$ & Over & 1.232 & 1.102 to 1.377 & $<0.001$ \\
\hline Floss & Yes & No & 1.157 & 1.049 to 1.276 & 0.004 \\
\hline Alcohol & No & Yes & 2.694 & 2.453 to 2.958 & $<0.001$ \\
\hline Live with tobacco user & No & Yes & 1.261 & 1.139 to 1.396 & $<0.001$ \\
\hline (Offered tobacco past month) & No & Yes & 22.860 & 5.341 to 97.870 & $<0.001$ \\
\hline (Friends think “cool”) & No & Yes & 0.969 & 0.739 to 1.272 & 0.822 \\
\hline Friends make fun & Yes & No & 0.828 & 0.752 to 0.912 & $<0.001$ \\
\hline Friends avoid tobacco & Yes & No & 1.500 & 1.346 to 1.671 & $<0.001$ \\
\hline Age-by-gender & NA & NA & 1.097 & 1.040 to 1.156 & $<0.001$ \\
\hline Age-by-offered & NA & NA & 0.859 & 0.781 to 0.945 & 0.002 \\
\hline Group-by-Think-“cool" & NA & NA & 1.633 & 1.132 to 2.356 & 0.009 \\
\hline
\end{tabular}

$\star$ Main effects not to be interpreted, because thay are part of significant interactions, are in parentheses.

$\mathrm{OR}=$ odds ratio $\mathrm{CI}=$ confidence interval.

$\mathrm{NA}=$ not applicable $; \mathrm{U} / \mathrm{C}=$ underweight or content with weight.

engagement in health-risk behaviours such as drinking alcohol and riding in cars without wearing seat belts, and avoiding healthpromoting behaviours such as flossing their teeth. It has been suggested that concern about weight predicts smoking incidence in adolescent females, ${ }^{17}$ but the lack of interaction with gender in these analyses suggests the effect is comparable across boys and girls, when the other components of the model are taken into account. It should be noted, however, that more than twice as many females as males in this sample considered themselves overweight $(28.2 \%$ vs $12.5 \%$, respectively). Overweight young people, especially girls, should be considered for early or more vigorous tobacco prevention efforts and/or weight control.

The finding that alcohol consumption predicted initiation of tobacco use corroborates cross-sectional correlations between use of the two substances. ${ }^{3}$ However, numerous studies have identified young people for whom tobacco use preceded alcohol use. ${ }^{18}$ Recent studies suggesting that the effects of nicotine found in tobacco may facilitate the addictive effects of other substances, such as alcohol, ${ }^{19}$ may partially account for increased rates of multiple substance use. The exact order of initiation of substance use may be less critical, however, than the implications of using any psychoactive substance during youth. Use of tobacco or alcohol may be indicative of social variables that promote such use and which should be addressed.

Social variables proved to be important predictors in the present analyses: living with a tobacco user and lacking friends who avoid tobacco users were associated with greater rates of initiation. The curious finding that having friends who "make fun" of smokers was associated with increased likelihood of smoking initiation may be a real phenomenon, when the remainder of the factors are held constant, as they were in this simultaneous model. This potential relationship remains paradoxical and is a candidate for increased scrutiny in replication studies.

THEORETICAL DISCUSSION

The story is a familiar one: the likelihood of initiating tobacco use increases with age, differs by gender, is related to other risk practices, and is predicted by exposure to social processes such as peer prompting and social consequences, and behavioural modeling. Similar findings have been reported from both cross-sectional predictions of current adolescent tobacco use and prospective studies of incidence. ${ }^{3}$ However, our data constitute an important addition to the literature by extending the predictive ability of the present variables up to a two-year interval post-baseline.

These findings were predicted from learning theory. The theory posits behaviour as controlled by an extensive history of both antecedent events, such as prompts from peers, and consequent events, such as praise and further encouragement and other social benefits, as well as physiological effects of psychoactive substances, resulting in "contingencies of reinforcement" for the behaviour. The theory accounts for generalised classes of behaviour, such as risk-taking, in which consequences which change the probability of one member of the class can also change the probability of the other members in the class. ${ }^{9}$

It is likely that peers who exhibit risk behaviours serve as models for each other to imitate. ${ }^{20-22}$ These peers may provide explicit prompts to each other for engagement in the practices, and provide reinforcing consequences, all of which serve to increase the future probability of the behaviour among members of the peer group. Indeed, Kelder and associates ${ }^{23}$ have shown that individuals' rates of health-related behaviours (specifically, smoking, exercise, and proper dietary choice) may be established as early as sixth grade (usually around 12 years of age), and tend to change in similar directions and magnitudes as 
their peers. Additionally, while smoking family members can also serve as models, young people who have a best friend who smokes have been found to be three times more "susceptible" to smoking. ${ }^{24}$

This represents very different behavioural dynamics. Very clearly, one consequence for not imitating peers is that they may abandon the non-conforming person. While parents can impose various penalties for their children's misbehaviour, they cannot abandon their children. Young people may be sensitive to this difference in availability or durability of social attention, and work harder to avoid losing peer approval than parental approval. This adds to the importance of intervening with the peer network.

Peers who exhibit risk behaviours are likely to prompt one another to engage in the behaviours, and are also likely to provide appetitive consequences for engaging in the behaviour, or aversive consequences for declining to do so. As shown in figure 2 , initiation of tobacco use accelerates much more rapidly among 11-14 year olds who have been explicitly offered tobacco as compared with those who reported not having received such an offer. This association implies that young people have yet to develop the skills necessary to resist such peer prompting. Further, these young people may follow and be exposed to the same peer group and repeated prompts for many years. This finding suggests that interventions should target young people before 11 years of age, and provide explicit assertiveness skills training such that the prepared young people can then resist such offers.

Providing young people with skills to resist peer prompts to engage in health-risk behaviour is unlikely to be sufficient. Removal of young people from peer groups who provide such prompts, as much as possible, may be yet another necessary and desirable goal. Early interventions may extend the current approach, which is to portray smoking as "uncool", by encouraging young people to avoid peers who offer or encourage tobacco use. This may not be very feasible, however. Encouraging young people to avoid environments where high-risk peers and smoking behaviour are likely to be present may be a more viable alternative.

If tobacco use is conceptualised as part of a generalised response class of risk-taking behaviour, then peer pressure and consequences for engaging in other risk-taking behaviours may indirectly lead to an increase in tobacco use. In this context, interventions that address only tobacco use may need to target resistance to peer pressure to engage in several risk practices.

The importance of these social processes extends beyond the isolated peer groups to whole communities and even cultures. "Metacontingencies" describe contingent relations between practices of groups of people, such as communities and cultures, and the outcomes the practices bring to the groups. ${ }^{25}$ An operational definition of metacontingencies may be that as andividual is confronted with similar social prompts and consequences for specific behaviour in an increasing number of contexts, the behaviour will change in probabilo ity accordingly. Forty years ago, smoking wao highly prompted and reinforced by much of the community. Today it has becom $\overline{\bar{E}}$ increasingly likely that a smoker will be. confronted with (a) prompts to cease smoking? in non-smokers' presence, (b) aversive consequences for not obliging, and (c) positive. consequences for obliging. The probability that an individual will be presented witle prompts and consequences to engage or now engage in a particular behaviour can be viewed in terms of the density of those social contingencies. Assuming that the predictor $\overrightarrow{s u}$ observed in our study are accurate, we mas: begin to conceptualise widespread sociab contingencies and cultural metacontingencyid based interventions. How can we change the community's behaviour such that the densitg of prompts and consequences for avoiding tobacco use (and tobacco users) is increase enough to counteract the effect of isolated peet groups that provide opposing social influences

This approach requires, in part, a shift o甲 attention from specifically targeting the behavi iour of tobacco use, to targeting the non-usine peers' social behaviour. If, for example, a thir of all young people are at risk for experimenta@ tion with tobacco, we can intervene with tho other two-thirds who are at less risk. These lower risk young people can be taught tô prompt and reinforce their high risk peers? avoidance of tobacco use, of tobacco users, an of environments where tobacco use is likely to be present. Recent public health medio campaigns by the California Department of Health Services have begun to approximate this approach by emphasising short-tern? socially aversive consequences of smoking such as yellow teeth and the "uncool" aspecto rather than delayed consequences such as disease. However, this can be further refined big teaching children and adolescents to provide these types of prompts to each other. Flynig and colleagues ${ }^{26}$ have proposed a similar framework. However, theirs is based on a $\operatorname{cog}$ 을 nitive approach of changing attitudes towards smoking and non-smoking, normative beliefs? and intentions to smoke as primary targetso The learning theory approach suggests that peer interventions function to change attitudes, intentions, and the behaviour of smoking, such that the interventions need onl focus on the outcome of reduction of actuat tobacco use.

We are developing a template model fo health-risk behaviour that incorporates the्ष principles from learning theory within an eco $\frac{0}{0}$ logical perspective. ${ }^{27}$ This behaviouralecological model suggests that the behavioura $\$$ processes described above take place in the context of several social institutions in addition to the peer network - for example, school, family, church, legal system-and constitute both proximal and distal effects on behaviour. ${ }^{28}$ Young people are exposed to prompts and consequences for their behaviour from several sources simultaneously, and are always under 
some degree of influence from their own personal histories with these processes.

Recent preventive efforts have examined the usefulness of interventions that affect multiple social institutions simultaneously. Flynn and colleagues $^{26}$ demonstrated that a tobacco prevention programme which was simultaneously implemented in both youth-specific popular media and in school-based programmes were considerably more effective than the school-based programme alone. The elements of the combined programme which the authors proposed as important for its success were consistent with the notion of metacontingencies and the behaviouralecological model. The authors suggested that because the anti-tobacco prompts were provided through multiple sources simultaneously, it would provide the young people with a sense that anti-tobacco was the normative attitude, particularly among their peers because the programme used age-specific credible models. The learning theory-based behavioural-ecological model does not require perception of norms - the presentation of credible models from multiple simultaneous sources alone is predicted to alter the probability of the behaviour.

The importance of the media and marketing cannot be denied. ${ }^{29}$ Exposure to the various forms of media may be greater for young people than adults; therefore, it is not surprising that recent studies have concluded that media exposure may be a more important predictor of young peoples' "susceptibility" to experiment with tobacco ${ }^{24}$ than peer and family modelling. The popular media (such as television, theatre, radio) provide high-frequency models of tobacco use, usually in a glamorising or glorifying context, too. Compared with 40 years ago, young people spend more time exposed to the popular media. It may be that media exposure has increased at the expense of real social interaction: young people may spend more time watching Friends (a television programme) than maintaining friendships.

The influence that the media has over youth behaviour, however, is a function of growing up in a social environment which elevates that media to such importance. A general principle of behaviour states that infants and young people learn to imitate models because this often is more effective in producing reinforcing consequences than "trial and error". ${ }^{8}$ Further, in Western culture, young people are taught that people who appear in the popular media are exceptional models. The adulation of such people in the media may be viewed as a cultural practice maintained by metacontingencies, passed on from one member to another, particularly among peers. In addition to modifying the media's presentation of tobacco use, perhaps preventive efforts can be aimed at modifying the social environment that delegates such power to the media. These may be competing objectives, however, and will require further consideration.

Within the learning theory context, the media and other social prompts (as well as most programmes that are considered "educa- tional") are conceptualised as antecedents to behaviour. Although antecedent control is certainly important, consequences of behaviour are of primary importance. Antecedents only take control over behaviour when they reliably signal behaviour-consequence pairings. Unfortunately, the negative consequences of tobacco use are too delayed, and seem improbable from the perspective of the individual who is "only trying it out" and does not plan to use tobacco regularly. More proximal and powerful social consequences need to be stressed. Therefore, resources need to be shared among interventions that target both antecedents and consequences of behaviour.

Testing the behavioural-ecological model would be an enormous task. Our attempts to understand behaviour that occurs in the context of multiple determinants, including those both historical and contemporary, must necessarily be both limited and suggestive. The predictive usefulness of the small handful of variables we have examined here is encouraging but is not a full account. Given that the kind of data necessary for a more complete account are in many ways difficult to collect, we may be limited to a model in which a number of relationships between elements are independently verified. The findings presented here constitute part of the behaviouralecological model.

A few points need to be taken into account when interpreting the results of the present study. The odds ratios for most variables were small to moderate, but these may represent larger effect sizes that have been attenuated by measurement error. When framed in a public health perspective, that of population risks rather than risks for individuals, the small relationships may provide the basis for important behaviour change in the population. The generalisability of findings concluded from this sample of southern California orthodontic clinical practices may be a concern. Although the observed 30-day prevalence of tobacco use (entire sample: $6 \%$ at baseline) was lower than prevalences reported for the California state level $\left(9.3 \%{ }^{30}\right)$ and the national level $\left(15.7 \%{ }^{31}\right)$, the associations derived between predictors and tobacco use are not necessarily different across samples. All predictors included in the present analyses exhibited adequate variance. In addition, the findings presented here replicate and extend those of our previous cross-sectional analysis ${ }^{10}$ and, as noted previously, those drawn from other populations. Because parent education did not interact with any other variables in this analysis, it is likely that the observed associations operate similarly in other socioeconomic groups. This last point should be taken as tentative, however, because the education variable was dichotomous (whether a parent or someone the young person lived with had attended college or not) and third-order interactions (for example, age $x$ gender $\times$ parent education) were not tested.

Our study offers several improvements over previous attempts to describe the process by which adolescents begin smoking. Whereas 
few studies have reported extended prospective cohort data on health-risk behaviour of adolescents, extensive and rigorous tracking procedures resulted in retaining over $92 \%$ of the original sample of nearly 17000 adolescents for two years. This was the largest study of tobacco use and other health behaviours for adolescents in an orthodontic population published to date. The data consisted of explicitly theory-based social and demographic predictors of adolescent tobacco use. Few previous studies had adequate power to detect relationships with simultaneous adjustment for as many variables as in the current analyses. Further, although many epidemiological studies have failed to take cluster randomisation into account, ${ }^{32}$ which underestimates error variance and liberalises findings in the direction of greater significance, our study used appropriate statistical controls to account for the effect. The present study therefore replicates and extends the previous findings with a more stringent and appropriate test.

Future studies should examine the social processes involved with peer pressure, both for and against tobacco use, with an eye toward prevention as applied by the entire community. Studies should also consider these processes in the context of other risk practices which tend to occur together, and may develop by similar means, such as tobacco and alcohol use. The associations identified here are prospective but still require experimental manipulation, where possible, to identify causal pathways. However, dramatic and enduring reductions in tobacco use prevalence and incidence may only be possible when multiple components of the behavioural ecology (such as peers, family, product distributors, media, legal systems) are simultaneously shifted in the direction of impeding tobacco use and other risk practices among young people, and encouraging healthy alternatives.

This research was supported by funds provided by the Cigarette and Tobacco Surtax Fund of the State of California through the Tobacco-Related Disease Research Program of the University of California, Grant No 2RT0106, awarded to Dr Hovell, and by the Center for Behavioral Epidemiology and Community Health.
Her

1 US Centers for Disease Control. Cigarette smokingattributable mortality and years of potential life lostatributable mortality and years of potential

2 Cigarette smoking among American teens rises again in 1995. Ann Arbor: University of Michigan Survey Research
Cigarette smoking among American teens rises again in Center. Press release, 15 December 1995.

3 US Department of Health and Human Services. Preventing tobacco use among young people. A report of the Surgeon General. Atlanta, Georgia: Public Health Service, Centers for Disease Control and Prevention, Office on Smoking and Health, 1994 (US Government Printing Office No S/N 017-001-00491-0.)

4 Pierce JP, Gilpin E. How long will today's new adolescent smoker be addicted to cigarettes? Am $\mathcal{F}$ Public Health 1996;86:253-6.

5 Conrad KM, Flay BR, Hill D. Why children start smoking cigarettes: predictors of onset. Br $\mathcal{F}$ Addict 1992;87:1711 24 .
6 Flay BR, Petraitis J. Methodological issues in drug use prevention research: Theotetical foundations. In: Laekefeld CG, Bukoski WJ, eds. Drug abuse prevention interventiont research: methodological issues. NIDA monograph No $1 \mathrm{Q}$ Washington, DC: US Government Printing Office, 1991:81-99.

7 Best JA, Brown KS, Camron R, Manske SM, Sante S. Geng der and predisposing attributes as predictors of smoking onset: Implications for theory and practice. $\mathcal{F}$ Health Edu 1995;26 Suppl:S52-60.

8 Skinner BF. Science and human behavior. New York: Freo Press, 1953.

9 Catania AC. Learning. New Jersey: Prentice-Hall, 1984.

10 Hovell MF, Slymen DJ, Keating K, et al. Tobacco use preva lence and correlates among adolescents in a cliniciare initiated tobacco prevention trial. $\mathcal{F}$ Epidemiol Communit Health 1996;50:340-6.

11 Hovell MF, Slymen DJ, Jones JA, et al. An adolescerfy tobacco-use prevention trial in orthodontic offices. $A m$ f Public Health 1996;86:1760-6.

12 Morrison TC, Wahlgren DR, Hovell MF, et al. Tracking and follow-up of 16,915 adolescents: Minimizing attrition bias. Controlled Clin Trials. In press.

13 US Department of Health and Human Services. Reducin the health consequences of smoking: 25 years of progress. A report of the Surgeon General, 1989 . Rockville, Maryland? Public Health Service, Centers for Disease Control, Offict on Smoking and Health, 1989. (DHHS Publication N\& (CDC) 89-8411.)

14 Statistics and Epidemiology Research Corporation. EGREO manual. Seattle, Washington: SERC, 1990.

15 Norusis MJ. SPSS/PC+Base system user's guide: version 5. $\alpha$ Chicago, Illinois: SPSS, 1992.

16 Maddahian E, Newcomb MD, Bentler PM. AdolescentsD substance use: impact of ethnicity, income, and availability. Adv Alcohol Substance Abuse 1986;5:63-78.

17 Camp DE, Klesges RC, Relyea G. The relationship between body weight concerns and adolescent smoking. Healt h Psychol 1993;12:24-32.

18 US Department of Health and Human Services. The healt consequences of smoking: nicotine addiction. A report of the Surgeon General, 1988. Rockville, Maryland: Public Healt Service, Centers for Disease Control, Office on Smokin and Health, 1988. (DHHS Publication No (CDOg 88-8406.)

19 Fowler JS, Volkow ND, Wang GJ, et al. Inhibition of monoamine oxidase B in the brains of smokers. Naturg 1996;379:733-6.

20 Bandura, A. Influence of a model's reinforcement contin gencies on the acquisition of imitative responses. $\mathcal{F}$ Person. ality Soc Psychol 1965;1:589-95.

21 Gewirtz JL, Stingle KG. Learning of generalized imitatio as the basis for identification. Psychol Rev 1968;75:374-970

22 Guerin B. Analyzing social behavior: behavior analysis and the social sciences. Reno, Nevada: Context Press, 1994.

23 Kelder SH, Perry CL, Klepp K, Lytle LL. Longitudina tracking of adolescent smoking, physical activity, and food choice behaviors. Am f Public Health 1994;84:1121-6.

24 Evans N, Farkas A, Gilpin E, Berry C, Pierce JP. Influence of tobacco marketing and exposure to smokers on adoles= cent susceptibility to smoking. I Natl Cancer Ins 1995;87:1538-45.

25 Glenn SS. Contingencies and metacontingencies: Relations among behavioral, cultural, and biological evolution. In. Lamal PA, ed. Behavioral analysis of societies and cultur@ practices. New York: Hemisphere, 1991.

26 Flynn BS, Worden JK, Secker-Walker RH, Badger GJ, Geto ler BM, Costanza MC. Prevention of cigarette smokingr. through mass media intervention and school programs

27 Willems EB. Behavioral technology and behavioral ecologx f Appl Behav Anal 1974;7:151-65.

28 Hovell MF, Hillman E, Blumberg E, et al. A behaviora ecological model of adolescent sexual development: a tem plate for AIDS prevention. $\mathcal{F}$ Sex Res 1994;31:267-81. -

29 Pierce JP, Gilpin E. A historical analysis of tobacco marke ing and the uptake of smoking by youth in the Unite States: 1890-1977. Health Psychol 1995;14:500-8.

30 Burns D, Pierce JP. Tobacco use in California 1990-199f? Sacramento: California Department of Health Services 1992.

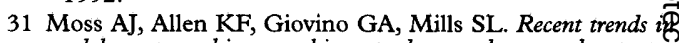
adolescent smoking, smoking-uptake correlates, and expectoc tions about the future. Advance Data No 221 . Hyattsville MD: National Center for Health Statistics, 1992.

32 Simpson JM, Klar N, Donner A. Accounting for cluster randomization: A review of primary prevention trials, 1998 through 1993. Am $\mathcal{F}$ Public Health 1995;85:1378-83. 